\title{
Performances da escrita na narrativa contemporânea: a voz do outro em "Totonha", de Marcelino Freire
}

\author{
Performances of writing in contemporary narrative: \\ The other's voice in "Totonha", by Marcelino de Freire
}

Rejane Pivetta de Oliveira ${ }^{1}$

Centro Universitário Ritter dos Reis - Rio Grande do Sul - Brasil

\author{
$\diamond$
}

\begin{abstract}
Resumo: O artigo propõe a reflexão sobre o papel da escrita na representação do outro excluído do universo letrado, tomando por base o conto "Totonha", de Marcelino Freire, integrante da coletânea Contos negreiros (2005). O tema é abordado à luz de problematizações acerca da escrita do outro evidenciadas pela etnografia (GEERTZ, 1989; Clifford, 1998), e na perspectiva política das divisões sociais geradas pelo exercício da escrita (RANCIÈRE, 2004, 2005). Ao final, pretende-se elucidar a hipótese de que a escrita de Marcelino Freire encena o paradoxo de dizer o outro no seio de uma escrita performática (RAVETTI, 2003), que se apresenta como resistência ao sistema dominante de significação do outro.
\end{abstract}

Palavras-chave: Leitura; Escrita; Dominação; Alteridade; Marcelino Freire

\begin{abstract}
The article proposes a reflection on the role of writing in the representation of the other excluded from the literary universe, based on the short story "Totonha", by Marcelino Freire, which integrates the collection Contos negreiros (2005). The question is analyzed in the light of problematizations about writing of the other evidenced by ethnography (Geertz, 1989; Clifford, 1998), and from the perspective of a political criticism of social divisions generated by exercise of writing (Rancière, 2004, 2005). At the end, we intend to elucidate the hypothesis that writing Marcelino Freire enacts the paradox to say the other within a performative writing (Ravetti, 2003), which presents itself as resistance to the dominant system of signification of the other.
\end{abstract}

Keywords: Reading; writing; Domination; Otherness; Marcelino Freire

\section{A escuta do outro}

De que modo a escrita é capaz de construir a imagem do outro iletrado? Eis a tensão constitutiva de "Totonha", pequeno conto de Marcelino Freire ${ }^{2}$, presente na coletânea Contos negreiros. A escrita de Marcelino Freire problematiza o discurso sobre o outro excluído, cuja história sempre foi contada em palavras alheias.

\footnotetext{
1 Doutora em Teoria da Literatura (PUCRS), professora e coordenadora do PPG Letras UniRitter.

2 Marcelino Freire é um dos mais influentes escritores da literatura brasileira contemporânea. Entre suas obras, destacam-se Angu de Sangue, 2000; BaléRalé, 2003, Contos Negreiros, 2005 (ganhador do Prêmio Jabuti), Rasif, mar que arrebenta, 2008; Amar é crime, 2010; Nossos ossos, 2013. É um dos contistas das antologias Geração 90 (2001) e Os Transgressores (2003), publicadas pela Boitempo Editorial. Como agente cultural, destaca-se por ser o idealizador da Balada Literária,
}

Dizer o outro é tarefa, em princípio, assumida por quem domina os meios de representação, desde uma posição central e legitimada. Tal situação estabelece, de pronto, uma hierarquia entre aquele que fala/escreve e o outro que é falado/escrito. Em Contos negreiros, Marcelino Freire tensiona essa ordem, conferindo um novo destino às personagens marginais, historicamente invisibilizadas e silenciadas pelos discursos hegemônicos.

\footnotetext{
festa que acontece em São Paulo, de forma descentrada, tanto em bares da Vila Madalena, como em centros culturais e bibliotecas espalhados por vários locais da cidade, centrais e periféricos. Também é editor da Coleção 5 Minutinhos (2002), pela Editora EraOdito, que publica livros inéditos, de nomes como Glauco Mattoso, Valêncio Xavier e Manoel de Barros, distribuídos gratuitamente. Em 2003, lançou a segunda versão da Coleção, desta vez infantil, reunindo Laerte, Luis Fernando Verissimo, Haroldo de Campos, entre outros. In: <http://marcelinofreire.wordpress com/2013/09/16/balada-do-esquecimento/>.
} 
A obra traz, no seu título, referência aos versos de Navio Negreiro ${ }^{3}$, de Castro Alves, que cantam os horrores vividos pelos escravos negros na travessia oceânica para o trabalho forçado nas plantações do Brasil-colônia. Se no poema sobressai-se a voz grandiloquente e a dicção erudita do "poeta dos escravos", incrédulo diante do destino desgraçado de "homens negros", "negras mulheres" e "magras crianças", nos contos de Marcelino Freire esses personagens não são objeto de nenhuma comoção, não são vistos por um olhar externo, senão que ocupam o lugar de protagonistas e narradores de todos os "contos negreiros". Se no poema de Castro Alves os negros existem na sua condição de seres miseráveis, aprisionados no “... porão negro, fundo, / Infecto, apertado, imundo, / Tendo a peste por jaguar...", nos contos de Marcelino Freire as personagens negras não se conformam à fatalidade de um destino infame. Os textos de Freire inscrevemse em um outro cenário histórico, marcado por uma reivindicação política, que reclama um poder de agência do outro subalterno, todavia excluído dos sistemas de representação, em que a escrita ocupa lugar privilegiado. Nesses termos, de que forma a representação do outro analfabeto pode escapar à contradição de tomá-lo como objeto do discurso, ao mesmo tempo que busca instituirlhe um lugar de fala?

O dilema parece incontornável, restando explicitar as tensões que decorrem do processo de representação. Essa é a estratégia de Marcelino Freire, que converte a escrita sobre outro iletrado em performance da oralidade. A voz é reforçada pela estrutura dramática dos contos, pelo ritmo da cantoria e do repente, pelas rimas, frases curtas e interrogativas, com apelo a um interlocutor pressuposto, enfim, toda uma dicção que remonta às tradições das poéticas orais. Além de ressaltar na escrita a memória da oralidade, trazendo ao centro da cena personagens marginalizadas que falam em primeira pessoa, Marcelino Freire expõe situações que costumam contrariar o senso comum, questionar os conceitos por meio dos quais a realidade tende a ser interpretada. Por exemplo, em "Vaniclélia", a prostituta enumera as vantagens da exploração sexual estrangeira (circular por aeroportos, conhecer países diferentes, o que lhe parece mais interessante do que estar casada com um homem "barrigudo" que a maltrata). Em "Esquece", o assaltante questiona o sentido geralmente atribuído à violência ("Violência é o carrão parar em cima do pé da gente e fechar a janela de vidro fumê..."); em "Nação Zumbi", o personagem lamenta a proibição do comércio de órgãos, pois isso garantiria a ele uma boa fonte de renda, caso pudessse vender o próprio rim, já que se trata de um

\footnotetext{
3 Disponível em: <http://www.dominiopublico.gov.br/download/texto/ bn000074.pdf>. Acesso em: 10 out. 2014.
}

bem que lhe pertence. Assim como esses, encontramos, em Contos negreiros, tantos outros exemplos em que a personagem narradora, sempre negra e pobre, reverte o ponto de vista oficial e institucionalizado sobre temas sociais.

Tal é o que acontece particularmente em "Totonha", personagem cujo discurso institui-se a contrapelo das vozes que afirmam os benefícios da leitura e da escrita, propalados pela escola e pelas campanhas governamentais em prol da alfabetização. A posição da personagem desconstrói certas ideias prontas no que toca à aquisição do código formal da língua, revelado como mecanismo reforçador de preconceitos e desigualdades que supostamente o processo de alfabetização deveria reduzir. Totonha recusa-se a ser "salva" ou "resgatada" da ignorância das letras, num gesto de resistência aos poderes de dominação da escrita, vista como instrumento que, ao contrário de emancipar, colabora com a manutenção das desigualdades e das condições de subalternidade do sujeito.

$\mathrm{Na}$ tarefa de "escrever a voz do outro", Marcelino Freire vale-se de uma estratégia que exige do leitor uma atitude de escuta, posto que o discurso da personagem constitui-se como uma fala. Ouçamos, pois, Totonha:

Capim sabe ler? Escrever? Já viu cachorro letrado, científico? Já viu juízo de valor? Em quê? Não quero aprender, dispenso. Deixa pra gente que é moço. Gente que tem ainda vontade de doutorar. De falar bonito. De salvar vida de pobre. O pobre só precisa ser pobre. E mais nada precisa. Deixa eu, aqui no meu canto. Na boca do fogão é que fico. Tô bem.

Já viu fogo ir atrás de sílaba? O governo me dê o dinheiro da feira. O dente o presidente. E o vale-doce e o vale-lingüiça. Quero ser bem ignorante. Aprender com o vento, ta me entendendo? Demente como um mosquito. Na bosta ali, da cabrita. Que ninguém respeita mais a bosta do que eu. A química.

Tem coisa mais bonita? A geografia do rio mesmo seco, mesmo esculhambado? O risco da poeira? O pó da água? Hein? O que eu vou fazer com essa cartilha? Número?

Só para o prefeito dizer que valeu a pena o esforço? Tem esforço mais esforço que o meu esforço? Todo dia, há tanto tempo, nesse esquecimento. Acordando com o sol. Tem melhor bê-á-bá? Assoletrar se a chuva vem? Se não vem? Morrer, já sei. Comer, também. De vez em quando, ir atrás de preá, caruá. Roer osso de tatu. Adivinhar quando a coceira é só uma coceira, não uma doença. Tenha santa paciência!

Será que eu preciso mesmo garranchear meu nome? Desenhar só pra mocinha aí ficar contente? Dona professora, que valia tem o meu nome numa folha de papel, me diga honestamente? Coisa mais sem vida é um nome assim, sem gente. Quem está atrás do nome não conta? No papel, sou menos ninguém do que 
aqui, no Vale do Jequitinhonha. Pelo menos aqui todo mundo me conhece. Grita, apelida. Vem me chamar de Totonha. Quase não mudo de roupa, quase não mudo de lugar. Sou sempre a mesma pessoa. Que voa.

Para mim, a melhor sabedoria é olhar na cara da pessoa. No focinho de quem for. Não tenho medo de linguagem superior. Deus que me ensinou. Só quero que me deixem sozinha. Eu e minha língua, sim, que só passarinho entende, entende? Não preciso ler, moça. A mocinha que aprenda. $\mathrm{O}$ doutor. $\mathrm{O}$ presidente é que precisa saber o que assinou. Eu é que não vou baixar minha cabeça para escrever. Ah, não vou (FREIRE, 2005, p. 79-81).

Trata-se de um relato em que a escrita encena a voz da personagem, deixando evidente o caráter de performance, que transforma a letra em escuta da voz suplantada pelos dispositivos escriturísticos ${ }^{4}$ (CERTEAU, 1994), sob os quais as sociedades modernas constroem suas regras de dominação. Para Michel de Certeau, essas vozes foram "afastadas pela triunfal conquista da economia que, a partir da 'modernidade' (séculos XVII e XVIII), se titularizou sob o nome de escritura" (CERTEAU, 1994, p. 221). O conto de Marcelino Freire justamente problematiza as relações de poder inerentes aos processos de leitura do código escrito. Totonha, antes de mais nada, fala, mas sua voz não cabe na ordem do mundo letrado, sendo, por isso, performatizada numa escrita insubmissa, em contraposição aos poderes econômicos e administrativos, feitos para garantir a ordem e o controle. Contudo, o discurso que simula a voz de Totonha pertence ao universo erudito (e literário) da escrita, domínio por excelência do escritor letrado. O impasse aprofunda-se ainda mais se lembrarmos que se trata de tematizar a situação do sujeito iletrado no próprio seio da escrita. De que forma é possível ultrapassar a determinação da escrita que se impõe de maneira inevitável cada vez que se trata de dizer o outro, por si mesmo desprovido dos meios legitimados para tal?

\section{Dilemas da escrita}

O discurso de Totonha levanta-se contra a grande conquista da escrita, sobre a qual a civilização ocidental construiu a sua história em documentos e registros

\footnotetext{
4 O termo é usado por Michel de Certeau em $A$ invenção do cotidiano e tem, no contexto da argumentação do autor, o sentido de programação técnica da linguagem, submissão à lei e aos códigos estabelecidos, regime típico das sociedades modernas, em contraste com os símbolos ordenadores e plenamente significativos das sociedades antigas. Sendo assim, o termo assume para Certeau um sentido exatamente oposto ao que Roland Barthes denomina "escritura" ou "literatura" como a máxima expressividade da língua, não pela mensagem que ela transmite, pelo conteúdo, e sim pelo "trabalho de deslocamento" (2007, p. 17) que ela exerce sobre a língua. Para Barthes, a escrita/escritura é a maneira própria de pensar da literatura (s.d., p. 21), uma espécie de "grau zero" ou ne "neutralidade", livre de qualquer ordem fixa da linguagem (id.: 63).
}

impressos. É essa escrita científica e disciplinar, a serviço da dominação e do processo de colonização do outro, o alvo da resistência de Totonha, personagem, no entanto, configurada no domínio das letras.

Contudo, essa contradição, insuperável do ponto de vista do registro letrado da ficção literária, propõe uma redefinição do lugar da voz na escrita e, com isso, sublinha um novo modo de leitura, que questiona as hierarquias do regime da linguagem, fazendo acreditar que o oral é próprio de sociedades atrasadas e ignorantes, enquanto a escrita é sinônimo de progresso e conhecimento. No conto de Marcelino Freire, fica evidente que a voz de Totonha não tem nada de simples emissão mecânica de sons, pois a voz é um instrumento que marca uma tomada de posição da personagem, recusando o papel passivo de aprendiz. A voz de Totonha reclama, antes de mais nada, ser ouvida.

Totonha, embora não saiba escrever, sabe falar e contar histórias, tal como os narradores primitivos, que transmitem sua experiência e sua sabedoria às gerações futuras. No conto, a professora - representante do saber "científico" - ocupa o papel de ouvinte, de maneira análoga ao leitor fora do texto. Assim, a estratégia narrativa de Marcelino Freire marca um dissenso em relação às posições fixas, criando trânsitos entre a escrita e a oralidade, o falar e o escutar. Uma outra relação com a alteridade então se estabelece, uma vez rompida a dicotomia e a relação hierárquica entre os regimes oral e escrito de representação. Nesses termos, a leitura/ interpretação do outro ultrapassa a dimensão cognitiva e instrumental, pois não diz respeito unicamente à decodificação de signos escritos, mas a um exercício de interpretação de um conjunto de códigos culturais que dão sentido aos comportamentos e discursos humanos.

O problema da representação do outro pelo discurso alheio passa por uma crítica dos sistemas de significação cultural, tanto mais quando o próprio discurso que supostamente assume a defesa do iletrado não é por ele partilhado. Nesses termos, o conto de Marcelino Freire não escapa à aporia, pois a recusa de Totonha à cultura letrada é feita exatamente desse lugar de enunciação, paradoxalmente denunciado. Todavia, não se trata exatamente da negação da escrita pura e simplesmente, mas de um outro modo de leitura, evitando sua reafirmação como instrumento de controle usado por quem detém o poder de distribuí-la como benefício ou benesse. ${ }^{5}$ Tal

\footnotetext{
A ideia de distribuição dos bens culturais e estéticos remete ao conceito de "partilha do sensível”, proposto por Jacques Rancière, que estabelece a "existência de um comum e dos recortes que nele definem partes respectivas. Uma partilha do sensível fixa, portanto, ao mesmo tempo, um comum partilhado e partes exclusivas. Essa repartição das partes e dos lugares se funda numa partilha de espaços, tempos e tipos de atividades que determinam a maneira como um comum se presta à participação e como uns e outros tomam parte nessa partilha" (2005, p. 15). Importa, assim, saber que sujeitos e de que modo eles tomam parte na distribuição dos produtos artísticos e intelectuais.
} 
atitude explicita o papel político da escrita, que não reside no simples domínio de uma competência, mas na possibilidade de questionar as próprias representações letradas que não reconhecem outras formas de saber, tampouco a alteridade do outro, visto apenas como depositário e depositório da cultura dominante.

Análises de autores como Todorov ${ }^{6}$, Edwad Said $^{7}$ e Homi Bhabha ${ }^{8}$ desvelam o quanto o pensamento ocidental ergueu-se sobre a legitimação de modelos teóricos sustentados por esquemas perceptivos pretensamente universais, responsáveis pela construção de identidades marcadas por concepções profundamente etnocêntricas. $\mathrm{Na}$ história da exploração mercantil e das conquistas coloniais, o outro sempre foi alvo de curiosidade do homem branco e europeu, que o transforma em objeto de exploração, justamente por ser reconhecido como "atrasado", "primitivo" e incapaz de se desenvolver pessoal e socialmente.

Mesmo a antropologia, disciplina que assume a tarefa de descrever as práticas e comportamentos dos grupos humanos, geralmente apartados da "civilização", colabora para reforçar a imagem do outro como estranho, exótico, selvagem ou simplesmente bárbaro. Somente no século XX a etnografia, método privilegiado da investigação antropológica, passou a ser questionada como elemento determinante na "interpretação das culturas". Justamente a cultura é um conceito sem o qual o outro não pode ser pensado no âmbito da antropologia. Antropólogos culturais como Clifford Geertz (1989) entendem a cultura como uma estrutura de sentidos, um conjunto de práticas e manifestações que orientam os comportamentos humanos, cujas regras e lógicas de funcionamento, nem sempre explícitas, cabem ao antropólogo interpretar. O modo de conhecimento instaurado pela antropologia deriva inteiramente da discursividade que transforma os fenômenos observados em "descrição densa", aquela, segundo Geertz, capaz de construir uma leitura das complexas estruturas conceituais, "simultaneamente estranhas, irregulares e inexplícitas" (1989, p.7), que modelam os comportamentos de maneira sempre transitória.

A etnografia enquanto "descrição densa" implica um duplo olhar: não só o olhar que observa o outro, mas aquele

\footnotetext{
6 Todorov (2009), no título de seu livro Nós e os outros acentua essa distância hierárquica, mais do que uma questão de diferença, entre o "nós" como o grupo social a que pertenço, e os "outros", vistos como aqueles que não fazem parte desse grupo social. Ao reler a história do pensamento francês, o autor revela a construção do outro a partir do ponto de vista do centro, eleito como princípio de universalidade e generalização.

7 No clássico Orientalismos, Edwad Said (2003) aborda o processo intelectual e o sistema de conhecimento responsáveis pela construção da imagem do Oriente pelo Ocidente.

8 Em O local da cultura, Homi Bhabha (1996) trata sobre a construção do discurso de dominação que garante a superioridade do colonizador sobre os povos colonizados.
}

que se deixa observar na tarefa de interpretar o outro. $\mathrm{Na}$ etnografia tradicional, a linguagem é um espelho que pretende descrever os fenômenos de forma transparente, acreditando-se capaz de oferecer uma representação dos nativos como "realmente são". Os atos humanos fazem sentido dentro de determinadas estruturas de significação, cujos códigos precisam ser traduzidos e interpretados, sabendo-se, todavia, que nem tudo pode ser apreendido, pois o outro jamais será assimilável ou apropriado em sua alteridade.

Para Clifford Geertz (1989), a indagação sobre o outro sofre, no âmago do gesto de tornar familiar o que nos parece estranho, da insuperável distância que faz dele uma permanente incógnita. A despeito de sua diferença e irredutibilidade ao sentido, o outro não é uma categoria abstrata, mas um ser real e existente, que se apresenta, na perspectiva de Levinas (2009), como um "rosto", ou seja, alguém que reconhecemos como semelhante a nós (no cerne da sua diferença), numa relação face a face e responsável (que responde a), daí o necessário descentramento do eu como medida de toda a relação ética. A perspectiva de uma ética da alteridade (LEVINAS, 2009) está fundada na relação entre sujeitos, cada qual dotado das capacidades de falar, de discorrer e de agir. Portanto, é no discurso, na linguagem, que o sujeito afirma a sua condição humana e de ser político, para além da mera constituição biológica, pois o corpo é matéria que significa, é uma forma de habitar o espaço e de inscrever-se socialmente.

Nesses termos, a tarefa de descrever e significar o outro converte-se, o mais das vezes, em um gesto de violência, à medida que cerceia a manifestação do outro, na sua própria linguagem, nos termos de sua expressão. Submeter o outro a um quadro de referência é contribuir para a reprodução do mesmo, eliminando a diferença em favor da homogeneização dos sentidos. Tal atitude contém a negação do potencial emancipador da escrita enquanto ação política que, ao contrário de submeter o outro a um código, reconhece sua capacidade de transformar a si mesmo e as suas condições de existência, rompendo os dispositivos que o condenam à subalternidade.

No conto de Marcelino Freire, o reconhecimento da identidade do outro excluído passa pela articulação de uma estratégia narrativa que, no mínimo, problematiza a visão corrente que faz do domínio do código letrado uma garantia de emancipação do sujeito. Nesse contexto, importa saber o que significa para Totonha aprender a ler e a escrever, pergunta necessária para evitar qualquer a priori universal, que imponha formas de pensamento, ações, sentidos e valores sociais sobre o outro. Para tanto, conforme assinala Jacques Rancière, em $O$ mestre ignorante (2004), é necessário que o ponto de partida na relação com o outro aprendiz estabeleça-se num patamar 
de igualdade, rompendo a assimetria que faz do mestre o detentor de um conhecimento para o qual se deve "baixar a cabeça".

\section{Ler e escrever além da letra: a performance literária}

Se Totonha recusa a aprendizagem do código linguístico, por outro lado se mostra uma leitora atenta do mundo ao seu redor, revelando um olhar sensível sobre as coisas: "Tem coisa mais bonita? A geografia do rio mesmo seco, mesmo esculhambado? O risco da poeira? $\mathrm{O}$ pó da água? Hein?" (FREIRE, 2005, p. 80). A escrita a que Totonha se recusa é aquela meramente instrumental, sem sujeito: simples nome desenhado numa folha de papel.

Contudo, não se trata de invalidar a escrita, reacendendo a crítica platônica contida no $\mathrm{Fedro}^{9}$, mas de não se deixar dominar pela programação dos discursos. Nesses termos, a postura de Totonha é reveladora do processo de manipulação a que a aprendizagem da escrita se presta, sem de fato significar uma mudança nas relações de desigualdade que ela acaba, ao revés, por aprofundar. É a isso que Totonha reage, ou seja, à escrita como lugar de dominação e reprodução da subalternidade, conforme explicita a imagem final do conto: "Eu é que não vou baixar minha cabeça para escrever. Ah, não vou" (FREIRE, 2005, p. 81). "Escrever" e "baixar a cabeça" são gestos complementares, que implicam uma postura corporal, demonstrando que a escrita, para além de uma atividade mental, é também um ato, uma manifestação corporal, dotada de significação. Se associarmos a escrita ao gesto (pois escrever implica um movimento corporal), torna-se mais evidentes a associação com a oralidade, pois a linguagem humana é, originalmente, gesto e som. Portanto, a voz e a letra são elementos intimamente interligados, ambos constituem-se como enunciação de uma corpo, discurso indicativo da presença de alguém, de um sujeito.

Este é o jogo da performance constitutivo da escrita de Marcelino Freire, uma vez que desloca a letra do campo da atividade puramente intelectual e abstrata, para situá-la no espaço da gestualidade, recuperando a postura corporal associada ao ato de escrever. Assim, a escrita assume a posição ambígua de ser gesto e voz, caracterizando o ato performático por excelência: aquele

\footnotetext{
9 Platão (1989) refere-se à escrita como uma forma precária de registro do conhecimento, alcançado não por via da reprodução de caracteres impressos, mas em presença de interlocutores, por meio do diálogo, da conversação dialética conduzida pelo filósofo. A escrita, assim considerada, é secundária em relação à transmissão oral. Porém, na filosofia contemporânea, o privilégio é da escritura, conforme tematizado por Jacques Derrida (2008), opondo-se ao fonocentrismo, como presença e certeza da verdade. Não é este o ponto que nos importa focalizar, e sim a cisão entre as culturas letrada e oral, geradora de hierarquias e exclusões sociais.
}

que rompe com o esperado, com a ordem prevista e programada. Essa singularidade da performance é o traço captado por Guillermo Gómez-Peña, que a define como "um lugar onde a contradição, a ambiguidade e o paradoxo não são tolerados, mas estimulados" (GOMESPEÑA, 2005, p. 203). Na mesma linha, Graciela Ravetti afirma que

o repertório do performático é rebelde à representabilidade e refratário à necessidade de elaborar enredos para conferir inteligibilidade ao representado e, ainda, é escorregadio à interpretação, uma vez que sua condição consiste em expressar, agir, realizar. Alheio também às tentativas de redescrição totalizante das ações humanas, o performático conserva os vazios de sentido e as aporias, as incompreensões milenares, sem naturalizar $\mathrm{o}$ - ainda - não compreensível (2011, p. 45).

A performatividade da escrita de Contos negreiros também se institui pela inversão da moralidade socialmente estabelecida, pela ruptura irônica com o lugar-comum, constituindo-se, assim, como reação ao "corpo" estático das normas e padrões sociais. Em "Totonha", a voz reage às pressões do corpo institucional, emblematizado, no conto, pela escola e o governo. Totonha literalmente resiste com sua voz à imposição da letra morta e submissa, quando decide não baixar a cabeça para aprender as lições a que lhe quer obrigar a professora. Esse gesto da personagem pode ser descrito como "ato dentro de uma imagem", "fazer corporal" (RAVETTI, 2003, p. 32). Nesses termos, podemos associar a escrita de Marcelino Freire à reivindicação do corpo feita por Paul Zumthor:

\begin{abstract}
O corpo é o peso sentido na experiência que faço dos textos. Meu corpo é materialização daquilo que me é próprio, realidade vivida e que determina minha relação com o mundo. Dotado de uma significação incomparável, ele existe à imagem de meu ser: é ele que eu vivo, possuo e sou, para o melhor e para o pior. Conjunto de tecidos e de órgãos, suporte da vida psíquica, sofrendo também as pressões do social, do institucional, do jurídico, os quais, sem dúvida, pervertem nele seu impulso primeiro (ZUMTHOR, 2002, p. 28).
\end{abstract}

Embora Zumthor relacione a performance aos estudos da poesia oral, seus estudos contribuem justamente para recuperar o elemento corporal implicado na linguagem, nos termos de uma crítica ao processo de racionalização da palavra escrita, marcada pela cisão com as formas de percepção e conhecimento advindas do regime da oralidade. Desse modo, a escrita performática de Marcelino Freire empenha-se em questionar a prerrogativa da letra de conter um saber superior e 
legitimado. Por certo, esse lugar privilegiado da escrita determina lugares sociais, como bem aponta Jacques Rancière, para quem o conceito de escrita articula-se a modos de fazer, ser e dizer. Antes de definir um saber ou um poder, a escrita, para Rancière (1985), institui a posição e as condições do corpo na ordem social. É toda uma divisão do trabalho que a escrita acaba por decretar, uma vez que aqueles alijados do universo letrado acabam por desempenhar trabalhos que exigem força física, exaurindo o corpo na luta pela subsistência.

Tratando-se de uma habilidade que requer o domínio de um código altamente especializado, a escrita pertence ao âmbito das atividades intelectuais, de modo a permanecer excluída das esferas onde o trabalho exige esforço braçal. A separação entre o mundo da expressão escrita e as condições da realidade, entre o mundo do trabalho e o da linguagem diz das hierarquias de valor em relação às práticas discursivas no cotidiano. Para Rancière (1995), o caráter político da escrita articula-se aos modos como sua prática é estabelecida socialmente, promovendo relações mais democráticas ou de dominação.

Totonha não pertence ao universo da escrita, seu corpo fraco e envelhecido habita um outro lugar, não só geográfico, como cultural. O Vale do Jequitinhonha - onde é menos ninguém do que no papel - é o espaço em que Totonha convive entre seus iguais, onde todos a chamam e a conhecem por seu apelido, nele ela enxergase a si mesma e é reconhecida em sua alteridade. A escrita é totalmente estranha ao território da personagem, o qual demanda uma outra leitura, para além das palavras escritas: Capim sabe ler? Escrever? Já viu cachorro letrado, científico? Já viu juízo de valor? Em quê?

No mundo de Totonha, os signos significam de maneira diversa, não são dissociados da experiência que a vincula à comunidade onde habita. O soletrar de sílabas e o garranchear do nome, tal como ensina a cartilha, não têm nenhuma conexão com o cotidiano da personagem, são atos que não se ligam à sua própria vontade: $O$ que eu vou fazer com essa cartilha? Número? Só para o prefeito dizer que valeu a pena o esforço? O problema reside, portanto, na dicotomia entre mundo letrado e práticas cotidianas. No conto de Marcelino Freire, Totonha, a despeito de não dominar o código escrito, revela-se uma leitora perspicaz, com capacidade de traduzir a realidade em palavras plenas de sentido e poesia, que dizem do seu modo de ser e estar no mundo, que nada tem a ver com simplesmente aprender a escrever de forma mecânica o nome numa folha de papel, conforme manifesta à professora: Coisa mais sem vida é um nome assim, sem gente. Quem está atrás do nome não conta? A reivindicação de um nome com "alguém dentro" coloca em outros termos a relação com a escrita - não como simples comunicação formal, mas como possibilidade de construir novas formas de subjetivação e de reconhecimento da alteridade, uma escrita, afinal, que não apague a voz do sujeito, mas antes a faça ser ouvida.

A escrita performática de Marcelino Freire constitui um ato de intervenção simbólica e social que se reveste de inevitável caráter político, à medida que recusa as práticas discursivas que assimilam o outro a padrões, gostos e normas dominantes, colaborando para o seu embrutecimento, em nome, muitas vezes, da sua emancipação. Totonha explicita de que modo campanhas de alfabetização servem a propósitos elitistas, relegando o outro à posição de subalternidade. A fala de Totonha desconstrói a visão idealizada da leitura e da escrita, conforme apregoa o ideal escolar iluminista, como se a simples condição de alfabetizado garantisse, em um só passo, acesso ao conhecimento e ascensão na hierarquia social. Como assinala Rancière (2004), importa, antes, saber em que medida a escrita traça o "veredito" da emancipação ou da dominação do outro excluído da cultura letrada.

Desse modo, ao desconstruir o lugar comum da consciência burguesa, Marcelino Freire faz o leitor indagar sobre as regras, a lógica e as estruturas que dirigem nossa visão e nossa relação com a alteridade, desnudando, enfim, o quanto existe de violência e autoritarismo quando a escrita converte-se no emudecimento da voz do outro. Assim, se em um primeiro momento o conto parece fazer a defesa da ignorância e do conformismo, por fim, revela-se como uma crítica aos modos de significação cultural que escrevem e inscrevem o outro como subalterno, ignorante, iletrado. A escrita de Marcelino Freire constrói um outro território de leitura, deslocando fronteiras entre letrados e iletrados e ainda rompendo com uma visão de leitura e escrita restritas ao domínio do alfabeto, dos códigos linguísticos, pois a inscrição do outro no mundo também se faz por gestos, rituais, imagens, símbolos, narrativas orais, enfim, uma série de outros modos de "textualizar significados" (CLIFFORD, 1998, p. 85).

"Totonha" constitui a emergência de uma outra escrita e de uma outra leitura, que se junta à entrada em cena de outras vozes, denominadas de marginais, identificadas a escritores organicamente inseridos no espaço geográfico e cultural das periferias das grandes cidades. A escrita de autores como Ferréz, Sérgio Vaz, Alessandro Buzo, Allan da Rosa, Sacolinha e tantos outros confere um novo ethos à representação de personagens socialmente marginalizadas, que enfim encarnam uma identidade e um destino que os colocam não apenas no papel estereotipado de seres miseráveis e violentos, como bandidos e criminosos, mas como sujeitos com uma história e maneiras de ser que demandam uma reconfiguração das molduras interpretativas construídas pela cultura erudita. De outra parte, essas obras revertem a imagem do outro 
visto como subalterno, marginal ou excluído, tomados como vítimas indefesas, pobres coitados inconscientes de sua condição e incapazes de falar por si mesmos.

Ironicamente, Totonha, uma analfabeta, tem muito a ensinar em matéria de leitura e escrita, reconfigurando os modos usuais de concebê-las. A "lição" de Totonha converte-se em gesto político que coloca em xeque o próprio lugar privilegiado da literatura como manifestação por excelência da cultura letrada - o que só se torna possível por meio de uma escrita performática que articula um outro território de interpretação, em que "aprender a ler" é, como ensina Totonha, uma forma de agência, de inscrição da voz do outro nas muitas escritas do mundo.

\section{Referências}

ALVES, Castro. Navio negreiro. Disponível em: <http://www. dominiopublico.gov.br/download/texto/bn000074.pdf>. Acesso em: 10 out. 2014.

BARTHES, Roland. O grau zero da escrita. Trad. Maria Margarida Barahona. Lisboa: Edições 70, [s.d.].

BARTHES, Roland. Aula. Trad. Leyla Perrone-Moisés. São Paulo: Cultrix, 2007.

BHABHA, Homi. O local da cultura. Trad. Myriam Ávila, Eliana Lourenço de Lima Reis, Gláucia Renate Gonçalves. Belo Horizonte: Editora UFMG, 1996.

CERTEAU, Michel. Cultura no plural. Trad. Enid Abreu Dobránszky. Campinas, SP: Papirus, 2012.

CERTEAU, Michel. A invenção do cotidiano. Trad. Ephraim Ferreira Alves. Petrópolis: Vozes, 1994.

CLIFFORD, James. A experiência etnográfica: antropologia e literatura no século XX. Trad. Patrícia Farias. Rio de Janeiro: Editora UFRJ, 1998.

DERRIDA, Jacques. Gramatologia. Trad. Miriam Chnaiderman; Renato Janine Ribeiro. São Paulo: Perspectiva, 2008.

FREIRE, Marcelino. Amar é crime. São Paulo: Edith, 2011.

FREIRE, Marcelino. Angu de sangue. São Paulo: Ateliê, 2000.

FREIRE, Marcelino. Balada do esquecimento, 2013. Disponível em: <http://marcelinofreire.wordpress.com/2013/09/16/baladado-esquecimento/>. Acesso em: 12 jan. 2014.
FREIRE, Marcelino. BaléRalé. São Paulo: Ateliê, 2003.

FREIRE, Marcelino. Contos negreiros. Rio de Janeiro: Record, 2005.

FREIRE, Marcelino. Nossos ossos. Rio de Janeiro: Record, 2013

FREIRE, Marcelino. Rasif, mar que arrebenta. Rio de Janeiro: Record, 2008.

GEERTZ, Clifford. A interpretação das culturas. São Paulo: LTC, 1989.

GÓMEZ-PEÑA, Guillermo. En defensa del arte del performance. Revista Horizonte Antropológico, Porto Alegre, v. 11, n. 24, p. 199-226, jul./dez. 2005. Disponível em: <http://www.scielo. br/scielo.php?pid=S0104-71832005000200010\&script $=$ sci arttext>.

LÉVINAS, Emmanuel. Entre nós: ensaios sobre a alteridade. Trad. Pergentino Pivato et al. (coord.). Petrópolis, RJ: Vozes, 2009.

PLATÃO. Fedro. Trad. Pinharanda Gomes. Lisboa: Guimarães Editores, 1989.

RANCIÈRE, Jacques. $O$ mestre ignorante: cinco lições sobre a emancipação intelectual. Trad. Lilian do Valle. São Paulo: Autêntica, 2004.

RANCIÈRE, Jacques. Políticas da escrita. Trad. Raquel Ramalhete et al. São Paulo: Editora 34, 1995.

RANCIÈRE, Jacques. A partilha do sensível. Trad. Mônica Costa Netto. São Paulo: Editora 34, 2009.

RAVETTI, Graciela. Performances escritas: o diáfano e o opaco da experiência. In: HILDEBRANDO, Antônio; NASCIMENTO, Lylei; ROJO, Sara (Org.). O corpo em performance. Belo Horizonte: NELAP/FALE/UFMG, 2003.

SAID. Edward W. Orientalismo: o Oriente como invenção do Ocidente. Trad. Tomás Rosa Bueno. São Paulo: Companhia das Letras, 2003.

TODOROV. Nós e os outros: a reflexão francesa sobre a diversidade humana. Trad. Sérgio Goes de Paula. Rio de Janeiro: Jorge Zahar, 1993. Vol. 1.

ZUMTHOR, Paul. Performance, recepção, leitura. 2. ed. São Paulo: Cosac Naify, 2002.

Recebido: 24 de abril de 2016.

Aprovado: 01 de setembro de 2016 .

Contato: pivetta.rejane@gmail.com 